\section{THE WORK OF THE JEFFERSON PHYSICAL LABORATORY}

A sYNOPSIS of all the scientific investigations which have been carried on in the Jefferson Laboratory since its foundation in $1884^{\prime}$ is beyond the scope of a brief notice. On the other hand, it is impossible to give a picture of our activities without a review of an extent sufficient to include the beginnings of those researches which are still in progress. Fortunately, it will not be necessary to go into much detail of description, since the eleven volumes of our "Contributions" contain a full account of all the results which have been obtained in the last dozen years.

The fact that this laboratory is not dominated by the work of any one man has led to a breadth of field in investigation rarely found in other similar institutions. The very number and variety of subjects, however, makes it difficult for a single individual to give an adequate account of the work as a whole. I have been freed from this difficulty by my colleagues, Professors Hall, Sabine, Davis and Bridgman, who have been kind enough to edit the account of their own researches.

Professor Hall's research work for many years has had to do with the flow of electricity and of heat in metals. $\mathrm{He}$ has published, usually in cooperation with others, various papers on thermal conductivity, on the Thomson effect, and on the electromagnetic and the thermomagnetic transverse or longitudinal effects in iron. Of late he has been occupied especially with the theories of electric and of thermal conduction, and of thermoelectric action, in metals. On this subject he published a paper in 1914, reaching the conclusion that "free electrons" play a much smaller part in conduction than many have supposed, but have an important function in thermo-electric action. In 1915, he published in $I l$ Nuovo Cimento a short paper suggesting that the positive ions in a metal, probably as numerous as the free electrons, may have much to do in the maintenance of an electric current. He is now engaged in developing this idea.

Professor Sabine is continuing his investigations in the varied problems of architectural acoustics. The results, so far published, are proving of value to architects in the correction of auditoriums and in their design in advance of construction. At present the experiments relate to the transmission of sound through the structure. While Professor Sabine has been working in one field he has stimulated a number of students in a variety of different subjects. Some of the researches for which he was originally responsible are still in progress; of these the work of Professor Bridgman and the investigations in the Schumann region will be mentioned in detail presently.

The work of Professor G. W. Pierce on high-tension currents was for many years carried on in this laboratory. It is, therefore, a great temptation to add interest to this notice by including an account of it here. However, as Professor Pierce is now under his own roof, it seems only fair to allow him to describe the activities of his own laboratory, should he care to do so, at some future time.

Notwithstanding that a large part of the time of Professor Duane is taken up at the Huntington Hospital by his work on the application of the radiations from radioactive substances to the treatment of cancer, he is a most active contributor to the research output of this laboratory. He has himself written several articles, theoretical and experimental, on the subject of X-rays, Radioactivity and Atomic Theory during the past year and he is at present directing the experiments of four students in the same fields.

The establishment of standards of wavelength and the study of the emission of gases and solids in the Schumann region has occupied me for the last fifteen years; recently I have succeeded in extending the spectrum, in the extreme ultra-violet, beyond the limit set by Schumann by an amount greater than that which Schumann achieved. There still remains, however, a considerable gap to be bridged before the region of the softest $\mathrm{X}$-rays is reached. Researches on the abiotic action of Schumann rays and a study of the volume ionization produced by them, have been completed in years past by Dr. Bovie and Pro- 
fessor Frederic Palmer. Researches on the photoelectric effect and on the reflection of metals in the extreme ultra-violet are now being conducted by Dr. Sabine and Dr. Gardner.

Professor Davis is chiefly occupied with thermodynamics, his work on the thermal properties of steam being somewhat widely known through Marks and Davis's "Steam Tables." At the present time he and $\mathrm{Mr}$. Kleinschmidt, a research student, are setting up the necessary apparatus for reproducing the international temperature scale with great precision by means of resistance thermometers, in the hope of verifying and completing some work of Professor Richard's along that line. Four other students have carried on experimental work under his direction; Dr. Trueblood on the Joule-Thomson effect in superheated steam, Dr. Romberg on the specific heat of water, Mr. Royster on the Joule-Thomson effect in thermometric gases, and $\mathrm{Mr}$. Loomis on the thermal properties of mercury vapor. The first two of these researches are nearly ready for publication; the last two are still in progress.

The work of Professor Bridgman is perhaps as well known as that of any member of our staff. I am indebted to him for the following summary: The thermodynamic properties of matter have been investigated under three main headings. The first heading has to do with the properties of liquids that do not freeze up to $12,000 \mathrm{~kg}$. The chief results were these: nearly all the liquids show a reversal of dilatation at high pressure, the dilatation at the higher temperatures becoming less than at lower temperatures. Beyond a certain pressure, the repulsive forces between the molecules predominates over the attractive forces so that work is stored up as pressure is increased. All liquids show persistent individual variations, doubtless in some way connected with specific molecular properties. The second heading has to do with melting curves. By examination of some 20 liquids, the characteristics of their melting curves at high pressure have been established; neither of the two theories, formerly accepted as correct, is true.
The melting curve neither ends in a critical point nor passes through a maximum, but continues to rise indefinitely, approaching a straight line at high pressure. The third heading has to do with polymorphic changes of solids. Some 150 substances have been examined and the phase diagrams of 30 substances have been studied and a number of new modifications have been found. The relations are most complicated and do not tend to any common type of behavior at high pressure. It is the rule that the phase of smaller volume is more compressible than the phase of greater volume and there are a number of cases in which the phase stable at higher pressures has a smaller specific heat. It can be definitely proved by these results that, at least in many cases, the centers of attractive force between the molecules are not located at their geometrical centers, but are probably close to the surface.

Dr. Chaffee's chief interests lie in the same field as those of Professor Pierce, but, as part of his work is still carried on in this building, it is fair to claim his study of oscillatory circuits as a product of this laboratory; as one result of this investigation he has perfected the "Chaffee Gap" a device of wide utility in wireless telegraphy.

Among the junior members of the teaching staff, Dr. D. L. Webster has recently turned his attention to the experimental study of characteristic $X$ radiation; thanks to the generosity of the General Electric Company, and by the use of the laboratory's 40,000-volt storage battery, he has already obtained some important results from a rhodium target. Dr. Clark has been at work on the study of the vibrations in a stretched wire; he is at present engaged in the design and construction of a deep-sea thermometer. Dr. Nusbaum is engaged upon the study of hysteresis loss in iron at very high frequencies.

There are in all twelve candidates for the doctorate at present at work on pieces of research or on theoretical problems; the fields of study of five of these men have been already mentioned; of the other seven, four are working in spectroscopy, a subject for which we are 
particularly well equipped, two are in electrodynamics and one in the study of viscosity of liquids.

The building in which all these researches are conducted is more than thirty-two years old, but, all things considered, it still serves its purpose very well. This is all the more remarkable when it is remembered that at the time when it was built there were few laboratories, either here or abroad, to serve as models. It is to the foresight of Professor John Trowbridge that the successful design of the Jefferson laboratory was largely due and it was his unselfish energy which made its equipment possible. Those who work in the building should ever keep these facts gratefully in mind.

\section{Theodore Lyman}

\section{Cambridge}

\section{SCIENTIFIC NOTES AND NEWS}

THE Society of American Bacteriologists will meet at New Haven on December 26, 27 and 28. There will be an adjourned meeting in New York on December 29 in affiliation with Section $K$ of the American Association. Members of program committee who have been requested, in opening the sessions under their charge, to review the work done in America in their field in bacteriology are as follows: Professor C.-E. A. Winslow, characterization and classification; Dr. F. G. Novy, protozoology; Professor C. E. Marshall, agricultural bacteriology; Professor F. P. Gorham, industrial bacteriology; Professor E. O. Jordan, sanitary bacteriology; Dr. W. H. Park, human pathology; Dr. V. A. Moore, comparative pathology; Dr. Erwin Smith, phytopathology, and Dr. D. H. Bergey, pedagogics of bacteriology. Those who have accepted invitations to speak at the dinner are Dr. A. C. Abbott, Dr. Herman M. Biggs, Professor H. W. Conn, Dr. J. J. Kinyoun, Professor W. T. Sedgwick, Dr. Theobald Smith, Dr. V. C. Vaughan and Dr. W. H. Welch.

To celebrate the eighty-sixth birthday (May 6) of Dr. Abraham Jacobi a dinner was given at the Ritz-Carlton, New York. Dr. Jacobi, emeritus professor of diseases of children in Columbia University, is in active hospital and private practise in New York City.

DR. RAYMond DoDGe, professor of psychology in Wesleyan University, has been appointed by the trustees of Columbia University to be Ernest Kempton Adams research fellow for the academic year 1916-17.

AT its meeting held May 10, 1916, the Rumford Committee of the American Academy of Arts and Sciences voted a grant of $\$ 500$ to Professor R. A. Millikan, of the University of Chicago, in aid of his researches on the photoelectric properties of metals in extreme vacua.

A GRANT of $\$ 300$ has been made from the C. M. Warren Fund of the American Academy of Arts and Sciences to Professor Grinnell Jones, of Harvard University, for work on the free energy of chemical reactions.

THE British Institution of Civil Engineers has made the following awards for papers read and discussed during the session of 1915-16: A Telford gold medal to Sir John Benton (Eastbourne); a Watt gold medal to Sir George Buchanan (Rangoon); a George Stephenson gold medal to Mr. F. W. Carter (Rugby), and Telford premiums to Mr. C. Carkeet James (London), Mr. D. E. MloydDavies (Cape Town), and Mr. W. T. Lucy (Oxford).

THE two annual Walker prizes in Natural History offered by the Boston Society of Natural History were this year awarded as follows: a first prize of one hundred dollars to Wilbert Amie Clemens for his essay entitled "An Ecological Study of the May-fly, Chirotenetes," and a second prize of fifty dollars to Carl Cheswell Forsaith, for his essay on "The Relation of Peat Deposits to the Formation of Coal." These prizes are annually offered for the best memoirs submitted on subjects in natural history, and while the composition is open to all, it was the intent of the founder of the prizes, the late William Johnson Walker, that they should serve as an encouragement for younger naturalists, rather than as a reward for mature investigators. 